\title{
Ensino Remoto Emergencial e a Lógica do Cisne Negro
}

\author{
Emergency Remote Teaching and the Black Swan Logic \\ Enseñanza Remota de Emergencia y la Lógica del Cisne Negro
}

Recebido: 12/01/2021 | Revisado: 14/01/2021 | Aceito: 17/01/2021 | Publicado: 20/01/2021

\author{
Abiezer Amarilia Fernandes \\ ORCID: https://orcid.org/0000-0002-6715-0367 \\ Centro Universitário de Brasília, Brasil \\ E-mail: abiezer.fernandes@uol.com.br
}

\begin{abstract}
Resumo
A Lógica do Cisne Negro é importante para o momento atual pelas lições pressupostas pelo autor, analista de riscos e matemático Nassim Nicholas Taleb. A Lógica do Cisne Negro tem por princípio, a fragilidade de conhecimentos através de aprendizados por observações e experiências. O Cisne Negro é um evento caracterizado pela tríade: raridade, impacto extremo e previsibilidade retrospectiva, elementos presentes no atual momento. $\mathrm{O}$ artigo tem por objetivo expor as estratégias aplicadas no curso de graduação em engenharia para o ensino emergencial remoto da disciplina Tópicos em Fontes Alternativas de Energia (TFAE), no contexto da pandemia por COVID-19, permeado por lições da Lógica do Cisne Negro. Relata-se experiências sobre a excepcionalidade do modus operandi da disciplina TFAE componente do último período da matriz curricular do curso de engenharia elétrica e requisito opcional para acesso à pós-graduação oferecida pela instituição. Discute-se estratégias institucionais bem como metodologias e estratégias específicas propostas para o ministério da disciplina TFAE. A efetiva participação discente e o consistente modelo de avaliação estão entre os resultados alcançados que consolidam a permanente necessidade de inovação em busca de adequações pedagógicas, reinventando modelos conservadores, lição preconizada na Lógica do Cisne Negro. Finalmente, a evolução da transformação digital e a importância do mindset digital conduzirão a um futuro modelo híbrido avançado para o ensino superior no pós-pandemia.
\end{abstract}

Palavras-chave: COVID-19; Ensino remoto; EaD; Lógica do cisne negro.

\begin{abstract}
The Black Swan Logic is important for the present moment because of the lessons assumed by the author, risk analyst and mathematician Nassim Nicholas Taleb. The Black Swan Logic has as a principle, the fragility of knowledge through learning from observations and experiences. The Black Swan is an event characterized by the triad: rarity, extreme impact and retrospective predictability, elements present in the current moment. The article aims to expose the strategies applied in the engineering undergraduate course for remote emergency teaching of the Topics in Alternative Energy Sources (TAES) discipline, in the context of the COVID-19 pandemic, permeated by lessons from the Black Swan Logic. Experiences on the exceptionality of the modus operandi of the TAES discipline, which is part of the last period of the electrical engineering course curriculum and an optional requirement for access to the postgraduate program offered by the institution, are reported. Institutional strategies as well as specific methodologies and strategies proposed for the ministry of TAES are discussed. Effective student participation and a consistent evaluation model are among the results achieved that consolidate the permanent need for innovation in search of pedagogical adjustments, reinventing conservative models, a lesson advocated in the Black Swan Logic. Finally, the evolution of digital transformation and the importance of the digital mindset will lead to a future advanced hybrid model for post-pandemic higher education.
\end{abstract}

Keywords: COVID-19; Remote teaching; E-learning; Black swan logic.

\section{Resumen}

La Lógica del Cisne Negro es importante para el momento presente debido a las lecciones asumidas por el autor, analista de riesgos y matemático Nassim Nicholas Taleb. La Lógica del Cisne Negro tiene como principio la fragilidad del conocimiento a través del aprendizaje de observaciones y experiencias. El Cisne Negro es un evento caracterizado por la tríada: rareza, impacto extremo y predictibilidad retrospectiva, elementos presentes en el momento actual. El artículo tiene como objetivo exponer las estrategias aplicadas en la carrera de ingeniería para la enseñanza remota de emergencias de la disciplina Temas en Fuentes de Energía Alternativa (TFEA), en el contexto de la pandemia COVID-19, permeado por lecciones de la Lógica del Cisne Negro. Se reportan experiencias sobre la excepcionalidad del modus operandi de la disciplina TFEA, que forma parte del último período del plan de estudios de la carrera de ingeniería eléctrica y requisito opcional para el acceso al programa de posgrado que ofrece la institución. Se discuten las estrategias institucionales, así como las metodologías y estrategias específicas propuestas para el ministerio del TFEA. La participación efectiva de los estudiantes y un modelo de evaluación coherente se 
encuentran entre los resultados alcanzados que consolidan la permanente necesidad de innovación en busca de ajustes pedagógicos, reinventando modelos conservadores, lección que propugna la Lógica del Cisne Negro. Finalmente, la evolución de la transformación digital y la importancia de la mentalidad digital conducirán a un futuro modelo híbrido avanzado para la educación superior pospandémica.

Palabras clave: COVID-19; Enseñanza remota; Educación a distancia; Lógica del cisne negro.

\section{Introdução}

A evolução gradual de perspectivas de mudanças no ensino superior presencial promovida pelo Ministério da Educação (ME) tem seu histórico iniciado em 2001 (ME 2001), avançando para 2004 (ME 2004), 2016 (ME 2016) e 2018 (ME 2018), onde Ministério da Educação disponibilizou para Instituições de Ensino Superior (IES), possibilidades de mudanças em cursos de graduação presenciais, através de metodologia não presencial mediada por Tecnologias de Informação e Comunicação (TIC).

Em 2019, (ME 2019), o Ministério da Educação publicou no Diário Oficial da União, a Portaria no 2.117 de 06 de dezembro de 2019 onde no seu Art. $2^{\circ}$, dispõe, para as IES, sobre a possibilidade de introduzir a oferta de carga horária na modalidade Ensino a Distância $(\mathrm{EaD})$ na organização pedagógica e curricular dos cursos de graduação presenciais até o limite de $40 \%$ da carga horária total do curso. O Art. $4^{\circ}$ da referida Portaria, determina a inclusão de métodos e práticas de ensinoaprendizagem que incorporem o uso integrado de TIC para realização dos objetivos pedagógicos. Caracterizam-se, nessas condições, processos normativos evolutivos de possibilidades de mudanças no ensino-aprendizagem na graduação presencial.

Mudanças essas, sensíveis para os padrões da graduação presencial, apesar de perspectivas positivas, a manutenção do modelo tradicional de ensino presencial, pode estar relacionado com o conceito de persistência institucional, traduzido na consolidação de instituições de se manter de forma permanente em determinado campo de atuação (Galegale \& Brólio, 2019).

Distante de quaisquer expectativas, um raro evento provocou profundas mudanças e impactou o cotidiano da sociedade mundial em dezembro de 2019. Surgiu uma nova doença que ficou conhecida como COVID-19 (Coronavirus Disease 2019) despertando o mundo para uma nova realidade. O vírus, o novo coronavírus (SARS-CoV-2) possui característica de média letalidade e alto grau de contaminação devido à velocidade de propagação (Arruda, 2020).

Decorridos três meses, o COVID-19 foi caracterizada pela Organização Pan-Americana da Saúde (OPAS) /Organização Mundial da Saúde (OMS) como uma pandemia (OPAS, 2020). Desde então, como prevenção sanitária imediata, a população passou a ser impelida e conscientizada a viver em sistema emergencial de isolamento sanitário, em decorrência da rápida disseminação mundial do novo vírus.

Os pontos de equilíbrio dos eixos sociais foram impactados e no eixo educacional não foi diferente. A disfunção universal assolou cada país de forma distinta e medidas emergenciais começaram a ser postas em prática. O Ministério da Educação, através da Portaria no 343 publicada em 17 de março de 2020, decidiu suspender as aulas presenciais, enquanto durar a situação de pandemia do novo coronavírus, substituindo por aulas em meios digitais (ME 2020).

Tal medida implicou em readequações nas instituições universitárias de todo o Brasil e no mundo, na velocidade própria de cada uma delas, na tentativa de dar continuidade ao ensino na graduação diante do novo cenário. Momento social complexo, com a percepção de uma transmutação radical das relações pessoais, estabelecidas por meio de decretos nacionais e pânicos mundiais decorrente do aumento de infectados e mortos pelo COVID-19 (Arruda, 2020).

Diante desse cenário de exceção originado na pandemia do COVID-19, é possível extrair lições da Lógica do Cisne Negro descrita em Taleb (2015). Para expor seu conceito, Taleb (2015) ilustra através de fato que surpreende pessoas do antigo mundo em deparar-se com o primeiro cisne negro, pois convencidas estavam de que todos os cisnes eram brancos. Trata-se de apresentar uma lição de quão limitado é o aprendizado por meio de observações ou experiências e a fragilidade de nosso conhecimento. 
O Cisne Negro, segundo Taleb, é um evento composto por três atributos assim descritos: Primeiro: O Cisne Negro é um outlier (dados espúrios em uma amostra estatística), pois está fora do âmbito das expectativas comuns, já que nada no passado pode apontar convincentemente para sua possibilidade. Segundo: Ele exerce um impacto extremo. Terceiro: Apesar de ser um outlier, a natureza humana faz com que desenvolvamos explicações para sua ocorrência após evento, tornando-o explicável e previsível. O terceto pode ser sintetizado como; raridade, impacto extremo e previsibilidade retrospectiva. É a pandemia do COVID-19, aqui caracterizada um evento tipo Cisne Negro.

Evidências mostram que o destino da humanidade mudou radicalmente nas mais diversas áreas e em especial, na do saber. A inércia diante daquilo que não se pode compreender Taleb (2015) objetiva identificar o que é, e como se beneficiar dele. Do Cisne Negro, emergem oportunidades até então não perceptíveis, sobretudo quando tratamos do tema ensinoaprendizagem em curso de graduação. Cabe a lição de que a estabilidade não permite evolução, há necessidade de fatores estressores para aprender a se adequar ao novo ambiente ou sobreviver (Taleb, 2015).

Experimentações inovadoras e revisões nas rotinas pedagógicas estão entre as medidas ágeis propícias para colocar o eixo educacional em novo ponto de equilíbrio, de tal forma, a atender o então ensino por meios digitais, ou ensino remoto suportado pelas ferramentas tecnológicas disponíveis. Com a proposta formal em Hodges (2020) e aqui adotada, o uso de termo específico cunhado para o tipo de instrução que está sendo ministrada nessas circunstâncias emergentes será: Ensino Remoto Emergencial (ERE).

Não obstante, o modelo ERE pode ser ministrado em tempo semelhante ao modelo presencial, com a transmissão definida de acordo com as grades horárias das aulas dos professores, no formato de lives. Tal transmissão permitiria a participação de todos de forma simultânea (Arruda, 2020). A lição da simplicidade de soluções, aqui se aplica, evitando buscas complexas que acabam dificultando novas descobertas (Taleb, 2015).

Prevalecem as distinções entre modelos ERE e EaD de forma a preservar possíveis equívocos pedagógicos. Enquanto as exigências que definem a modalidade $\mathrm{EaD}$, estão na preparação e formação do docente, na especificidade da infraestrutura, no material didático dedicado, no planejamento e no preparo conforme metodologia e conteúdos a serem ministrados, a modalidade ERE busca de forma ágil e segura utilizar recursos disponíveis da melhor forma possível para atender circunstancia emergencial.

A proposta deste artigo é descrever experiência vivenciada no ERE usando soluções de ensino totalmente remotas durante todo um semestre letivo, permeadas por lições da Lógica do Cisne Negro. Discutir resultados, sem a pretensão de recriar um modelo concorrencial robusto, mas fornecer acesso temporário ao ensino-aprendizagem de forma ágil e confiável enquanto perdurar o evento Cisne Negro. Este relato de experiência permite reflexões sobre as práticas desenvolvidas durante o exercício da docência na sala virtual, com discentes de graduação em engenharia. Entende-se que o compartilhamento de experiências dessa natureza poderá subsidiar práticas em desenvolvimento.

\section{Metodologia}

Trata-se de um relato de experiência sobre o modelo ERE na graduação do curso de Engenharia Elétrica do Centro Universitário de Brasília (CEUB), DF. O estudo trabalhou o lócus investigativo na disciplina TFAE, componente da estrutura curricular do curso de graduação, a partir de práticas de ensino remoto no período de agosto a dezembro de 2020, quando do término do segundo semestre letivo de 2020. É uma pesquisa qualitativa, acadêmica, com dados coletados diretamente no contexto de um acontecimento, utilizando metodologia de estudos de fenômeno social, segundo Pereira (2018), e pode ser caracterizada como um estudo de caso. Esse relato descreve as estratégias institucionais para enfrentamento da situação emergencial, uma breve descrição da disciplina, assim como, as metodologias e estratégias propostas para ministrá-la. Os resultados são discutidos mediante as ações desenvolvidas com desfecho nas considerações finais. 


\section{Estratégias e Métodos no ERE}

\subsection{Estratégias Institucionais no ERE}

No tratamento estratégico, vale destacar o Ambiente Virtual de Aprendizado (AVA), que, segundo Pereira (2007), é uma opção de mídia que está sendo utilizada para mediar o processo de ensino-aprendizagem à distância e que depende da qualidade dos atores envolvidos no processo pedagógico. Até então, o AVA era uma alternativa híbrida para aqueles que dispunham de qualidade de internet e dispositivos dotados de segurança para acessá-la em padrões não igualitários. Essa é uma realidade e elemento importante a ser considerado no modelo ERE, pois desatar o nó da desigualdade tecnológica ainda é um desafio.

Embora com experiência institucional no AVA, o momento atual, despertou discentes, docentes e a comunidade acadêmica em geral para um fato axiomático: a mediação de aulas por meio da tecnologia passou, de forma súbita, a um patamar até então inexplorado. O ambiente demonstrou ser volátil e arriscado, crescer e desenvolver nesse novo normal é o desafio.

Esse ambiente requer atenção especial a atributos como; domínio e segurança computacionais. Ao domínio computacional associa-se à fluência digital especialmente dos docentes acostumados com suporte individual em experiências com ferramentas online. Esse atributo deve ser contextualizado à realidade dos atores, independentemente da faixa etária ou fase do ensino. E quanto à segurança computacional, relaciona-se ao atendimento mínimo às particularidades de proteções contra vírus e invasões. Visto que as instituições de ensino têm a oportunidade de transmitir as aulas para grupos de discentes, com criatividade e de forma satisfatória, o atendimento a esses atributos, torna o exercício das atividades acadêmicas mais confiáveis.

Explorar as potencialidades das plataformas disponíveis na instituição, no curto prazo, de forma a permitir o uso imediato de ferramentas como contribuição eficaz na formação dos discentes na graduação, instigou mudanças. Adotadas as plataformas, Google Classroom e a de comunicação das salas virtuais Google Meet, plataformas lançadas pela Google, no G suíte for education. Dotadas de recursos que permitem a realização de vídeo-aulas, armazenamento de arquivos e integração de aplicativos, permitem também, a gravação e manutenção temporária de conteúdos ministrados, chats, agendamentos de tarefas, postagens de atividades individuais e coletivas, correção de atividades e atribuição de conceitos (Iftakhar, 2016).

É permitido link com o Google Drive ambiente onde são criadas as turmas no formato de arquivo de pastas com possíveis inserções de atividades e com arquivamento dos materiais nas nuvens (Silva, 2020). Existem flexibilidades operacionais como exclusão de ações concluídas, adição ou reexame de atividades a qualquer instante no sistema. Todos os registros ficam à disposição dos discentes para estudos, leituras e exercícios. As atividades avaliadas pelo docente podem ser devolvidas com comentários individuais e as menções são disponibilizadas aos discentes a critério do professor. A agenda de atividades com alertas para os discentes reduz a probabilidade de descuido quanto aos compromissos.

A participação nos meets é privativa, aqueles participantes que estiverem fora do domínio da instituição, necessitam de aprovação do organizador da sala para acesso ao ambiente virtual. Os meets são criptografados como medida de segurança contra possíveis invasores e eventuais vazamentos.

A intensificação de treinamentos do corpo docente foi uma estratégia institucional fundamental adotada para expandir os novos procedimentos de ensino, em especial, descobrir novos recursos computacionais Google. Diversas oficinas foram realizadas através de lives, gravadas e disponibilizadas, as dúvidas e esclarecimentos eram sanados online ou via canais de comunicação disponibilizados para essa finalidade. Tratamento similar sofreu o corpo discente, aqui as dúvidas eram solucionadas pelos próprios docentes, na medida em que, esses possuíam capacidade de resposta, ou por alunos monitores, especialmente preparados para a situação. 
Na sequência, a instituição decidiu ofertar à comunidade discente a opção de continuidade no convívio acadêmico sob as novas condições então impostas pela pandemia. As portas virtuais foram abertas em março/20 na modalidade ERE. A resposta positiva da comunidade acadêmica à modalidade contribuiu para impacto mínimo no calendário original e, consolidou o uso das tecnologias como referenciais mediadoras voltadas para a sustentação de conexões ensino-aprendizagem.

Observado o contexto institucional mundial e nacional, preservadas as singularidades e diferenças na forma de desenvolvimento, instituições internacionais e nacionais a exemplo da Universidade de Bristol no Reino Unido, da Universidade de Lisboa, em Portugal, da Universidade Estadual de Campinas (UNICAMP) e da Universidade de São Paulo (USP), seguiram estratégia similar de oferta de atividades de ensino remoto em março/20 (Arruda, 2020). Respeitada a capacidade de resposta de cada instituição, destaca-se, diante do cenário Cisne Negro, o benefício do senso de urgência das instituições para o desenvolvimento do mindset digital.

\subsection{Sobre a disciplina TFAE}

Ofertada com uma carga horária total de 75 horas, sendo 4 horas semanais divididas em dois dias de 2 horas cada, destinadas exclusivamente a estudos teóricos, não havendo prática em laboratórios. É uma disciplina componente do último período do curso de graduação de engenharia elétrica. Tem como proposta oferecer aos discentes conteúdos sobre conceitos, projetos, regulamentações e benefícios para a sociedade na aplicação de fontes alternativas para produção de energia elétrica. A disciplina permite aprofundamento em pesquisas e estudos relacionados a energias renováveis, tornando-se uma opção para acesso à pós-graduação oferecida pela instituição.

A ementa composta por módulos classificados por temas de estudo, permitia explorar trabalhos em grupos, discussões e apresentações, com aplicação de metodologia expositiva e dialogada alternando com salas de aulas invertidas. Quando em aulas virtuais, podendo ser realizadas de forma síncrona, quando professores e alunos interagem ao mesmo tempo ou de maneira assíncrona, quando a interação é realizada em momentos distintos, a segunda opção era mais usual. As avaliações através de exames escritos e presenciais nos moldes tradicionais permitia uma sensibilidade aguçada de aprendizado. Dada à excepcionalidade, foram revisadas as metodologias e estratégias de ensino, com forte impacto nas apresentações dos conteúdos e no sistema de avaliação de aprendizagem, como detalhados na sequência.

\subsection{Métodos específicos propostos no ERE}

A busca por metodologia ativa de aprendizagem preconizada em Bergmann \& Sams (2016), a necessidade de métodos inovadores segundo Moran (2015), e no aprender a se educar na era digital em Gómez (2015), induzem o professor nesse ERE, a criar e experimentar alternativas pedagógicas que possam ser realizadas pelos estudantes em ambiente de livre escolha, associando aprendizado e prazer nesse momento diferenciado da vida.

Adequação do material didático tornou-se foco primário das atenções desse docente para ministério das aulas do ERE, precavendo-se de possíveis fragilidades que pudessem emergir. Os conteúdos das aulas foram revistos e planejados com níveis de contextualização mais aprofundados, mais didáticos e com variações de metodologias (expositiva e dialogada, estudos de casos, sala de aula invertida) adequadas a cada tema de estudo. Explorar as apresentações com recursos dinâmicos adequados comporiam os elementos diferenciais das apresentações ao vivo.

Visando compensar as perdas perceptivas presenciais, quando em ambiente de sala de aula virtual, o planejamento das aulas deveria ser capaz de envolver os alunos de tal forma a permitir captar o mais sutil sinal perceptivo perdido. Todo o conteúdo programático da disciplina TFAE foi disponibilizado previamente aos discentes para acompanhamento do planejamento das atividades e utilização do material didático. 
Em Moore (1993), é citado que a educação é um processo social e que ocorre de forma construtiva e dialogada para que haja uma relação interativa entre os agentes da comunicação na sala de aula. Assim, buscando explorar mecanismos para uma relação interativa através de diálogos abertos, na fase inicial da disciplina, desenvolveram-se bate-papos abrangentes e contextualizados com os estudantes matriculados na sala virtual. Dentre os objetivos desses diálogos estavam; a identificação do perfil da turma, expectativas de aprendizagem, vivências com o ambiente virtual acadêmico, limitações estruturais para cursar a disciplina por meio do ERE e desdobramentos de assuntos afins. Os resultados apontaram para um índice elevado de heterogeneidade na turma. Com esse diagnóstico, novos ajustes foram necessários nas dinâmicas das ações planejadas, centrando-se nos anseios da turma e nas experiências com a temática da disciplina.

Pautado em exercícios dialogados, as agendas das aulas passaram a ser desenvolvidas em três fases cada qual com proposta específica de ambientar, difundir e discutir respectivamente os temas de estudos, conforme detalhado a seguir. Fase Um, momento de construir ambiente de provocações técnicas sobre questões objeto de estudos, aguçando para o tema central da aula e permitindo sensibilidade perceptiva do clima da turma. Fase Dois, vez de se difundir de forma dinâmica, o objeto de estudo, com tempo bem estimado e estrategicamente pausado permitindo intervenções através de chat, de forma a evitar o monólogo e a sensação de ausência virtual. Fase Três, ensejo de possibilitar discussões e debates sobre o assunto estudado com fartos exemplos reais e atuais. O tempo de duração de cada fase é flexível e variante conforme a natureza do assunto objeto da aula, bem como, pelo senso perceptivo capturado anteriormente do clima da turma. Foram evitadas opções metodológicas, que exigissem mudanças de ambientes virtuais especialmente dos discentes, como por exemplo, softwares de gamificação, não só pela possível limitação de estrutura tecnológica como pela possibilidade de evasão virtual.

$\mathrm{Na}$ organização das aulas, a prévia divulgação do link de acesso à plataforma, permitia melhor controle e cumprimento de agenda pelos discentes, sendo as presenças nas aulas computadas através de registros no chat pelos alunos. As manifestações ao longo das aulas eram realizadas de forma organizada quer verbal ou escrita via chat, sem atropelos ou sobreposição de falas. O uso adequado da opção mute enquanto participante-ouvinte evitou distorções no áudio, perceptíveis quando da reprodução das gravações.

O conteúdo ministrado como previsto no plano de ensino da disciplina, com a totalidade das horas dedicadas às atividades síncronas prioritariamente. Os materiais de apoio e os roteiros de entrega de atividades avaliativas eram postados semanalmente, sempre às sextas-feiras e no mesmo horário. No roteiro de orientação do discente, o envio das tarefas de avaliação de aprendizagem às terças-feiras em horário definido. A plataforma oferece sistema de controle de agenda eficiente para essa finalidade.

\subsection{Estratégias específicas propostas no ERE}

Manutenção da estrutura padrão do calendário acadêmico, com aulas preservadas no turno de origem dos discentes em horários e dias como presencial fossem e definição dos ciclos de avaliações tanto as parciais quanto a final. A estratégia visava assegurar uma agenda acadêmica, que não prejudicasse os compromissos dos alunos que em sua maioria participavam no mercado de trabalho no período diurno, independentemente da condição de home office.

A construção do diálogo educacional no ambiente virtual considerou premissas de Moore (1993), em que um diálogo é intencional, construtivo e valorizado por cada parte, constituindo uma interação com qualidades positivas influenciadas pelas variáveis: meios de comunicação, tipo de conteúdo, características dos professores e dos alunos. Dessa forma, no diálogo de TFAE utilizou-se de aulas síncronas que permitiram aos atores discutirem temas de estudos técnicos como; medidas, regulamentações do setor elétrico, estudos de cases e assuntos afins, via interação por áudio/vídeo, chats, em tempo real.

Inovação na estratégia de apresentações do conteúdo programático, explorando-se temáticas vibrantes e abundantes de detalhes, sustentadas por recursos de multimídia. Esse elemento de inovação foi inspirado em Horn \& Staker (2015), com 
citação de existência de inovações pontuais e profundas que modificam a educação formal, sendo capazes de proporcionar novas configurações híbridas, dinâmicas e integradoras.

Adequação do modelo de avaliação do aprendizado. Esse modelo considera a concepção das menções parciais a partir de resultados de grupos de atividades (ATs) propostas e a menção final gerada pela composição de menções parciais. Assim, para concepção de menções parciais foram definidos os quantitativos de grupos de ATs semanais, respeitando as datas limites do calendário acadêmico. As ATs eram propostas no modelo dissertativo e individual com objetivo de fortalecer o aprendizado. Cada AT tinha um objetivo definido para alcançar as habilidades e competências previstas o que conduziu o processo de correção a ser realizado pelo professor e não pelo recurso automático disponível na plataforma. Os resultados das ATs eram expressos de forma literal: positivos ou negativos. O quantitativo de resultados positivos era alocado em janela correspondente que por sua vez identifica a menção associada.

Um exemplo ilustrativo pode ser observado na Figura 1, em que a dimensão das janelas, a critério do professor, estabelece as faixas de abrangência das menções literais. Para um caso hipotético, onde de um total de sete atividades aplicadas, obteve-se um resultado de quatro atividades positivas, isso conduziria à janela de 4AT identificando a menção MS (Média Superior) e assim para os demais resultados com ATs positivas. Ainda sobre a dimensão das janelas, permite-se estabelecer grau de complexidade das ATs bem como o momento de sua aplicação. Na configuração da Fig.1, foram estabelecidas duas atividades de elevado grau complexidade (6AT e 7AT), duas de nível mediano (4AT e 5AT) e três de menor complexidade (1AT, 2AT e 3AT). Considerando que o aluno participe de todas as atividades é possível avaliar seu nível de aprendizado. O modelo permite múltiplas possibilidades de análises e penalização em caso falta de envio de atividade, no caso exemplo, a partir da segunda falta já não será possível ao aluno, alcançar a menção máxima.

Figura 1 - Janelas de Menções.

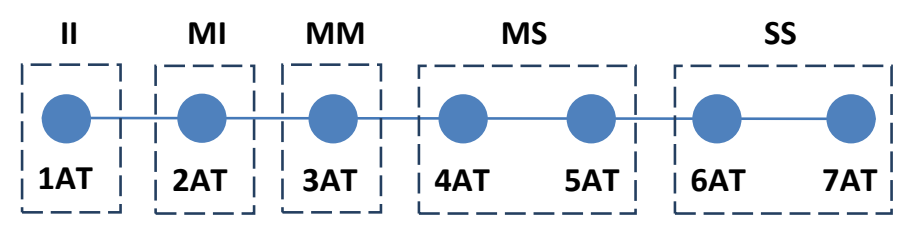

Fonte: Autor.

Legenda das menções literais: SS menção superior; MS média superior; MM média mínima para aprovação; MI média insuficiente; II menção insuficiente.

A tipologia da avaliação aplicada é de natureza formativa, dotada de característica diagnóstica, inclusiva, de mão dupla e não pontual, onde aspectos complementares como; objetivos e conteúdos foram avaliados e, as propostas de intervenções didáticas e os recursos utilizados como preconizado em Rabelo (1998).

\section{Resultados e Discussão}

No decorrer da disciplina, os alunos receberam instrumentos necessários para entendimento de conceitos, históricos e políticas do sistema elétrico no Brasil e no mundo, evoluções e perspectivas. Inseridas propostas para desenvolvimento de fundamentos acerca das necessidades da sociedade visando construir um saber múltiplo consoante com a dinâmica das regulamentações do setor.

No que tange a avaliação dos discentes matriculados, essa teve por objetivo, avaliar as habilidades e competências desenvolvidas no processo de desenvolvimento do aprendizado. Transcorreu de forma gradual e sistemática ao longo do 
período letivo permitindo ao professor avaliar a participação dos alunos nas atividades propostas considerando a trajetória do conteúdo aprendido durante a disciplina.

A participação dos alunos atingiu média de $85 \%$ ao longo do semestre letivo. O índice de evasão dos discentes foi de aproximadamente $10 \%$. Na busca pela identificação dos motivos e reversão da evasão, observou-se que os casos estavam relacionados à escolha inadequada da disciplina com o curso de origem e a problema de ordem particular.

Ao longo de todas as aulas, mecanismos de feedback eram acionados frequentemente para avaliação do modelo quanto; a ação metodológica do professor, as avaliações contínuas aplicadas, enfim, a preocupação do ensino-aprendizado como um todo de forma a avaliar a gestão do docente na disciplina TFAE nesse contexto de ERE.

O Cisne Negro evidenciou novas situações como; o ganho, pelo discente, de liberdade e autonomia dado pelo ambiente acadêmico virtual e por outro lado ele se defronta com a necessidade de realizar a autogestão, organizar o seu ritmo de aprendizagem, o tempo de dedicação aos estudos, além da necessidade de construir e assumir responsabilidades com a produção dos resultados de aprendizagem.

A exigência básica do uso de tecnologias digitais e o fato real das condições estruturantes distintas dos estudantes cabem reflexões constantes das atividades demandadas pelos docentes, de forma a não ocorrer situação que exclua a participação de aluno por condicionante tecnológica.

Por mais dinâmico que o ERE seja e mesmo com os mais diversificados dispositivos tecnológicos introduzidos para nortear demanda de atividades, nada se pode afirmar com precisão o quanto o foco e a atenção dos discentes podem ficar comprometidos, seja pela incapacidade desses de gerir seu tempo e organizar a rotina para dedicar-se às aulas, seja devido à dispersão natural provocada pelo ambiente em que se encontram.

Finalmente, o diagnóstico avaliativo final do modelo sob a ótica da turma, apontou que os alunos que concluíram a disciplina, em sua grande maioria avaliaram positivamente as estratégias bem como as metodologias pedagógicas desenvolvidas. Alguns depoimentos estão transcritos abaixo.

"Conforme já havia dito antes, o senhor é um excelente professor e encontrou um método de avaliar-nos e manternos antenados em sua disciplina como nenhum outro professor conseguiu, mostrando, além desse método, um domínio excepcional do que ensina e uma consistência em sua postura nas aulas que, na opinião da maioria dos alunos, não carece de mais polimentos".

"Obrigado professor, gostaria de agradecer as aulas e sua atenção ao meu caso e espero que suas aulas continuem ótimas pra melhores como sempre foram”.

"Professor gostaria de agradecer pela disciplina! Agregou bastante!"

"Professor, grato por vossa colaboração em mais um período de dificuldades, porém de grandes aprendizados. Espero ao final deste semestre estar formado, e, portanto, agradeço toda vossa colaboração”.

\section{Considerações Finais}

A disposição em inovar para tornar o ensino da graduação da engenharia mais espontâneo em cenário de Cisne Negro mostrou-se imperiosa considerando os impactos sociais e econômicos advindos do mesmo. Esforços intensos foram dedicados à construção de estratégias múltiplas de aprendizagem com a finalidade de gerar nos discentes maior interesses, envolvimento e participação. Resultados indicaram contribuição relevante para a melhor apreensão dos conceitos e conteúdos ministrados. 
Valores intangíveis como; respeito e empatia foram cultivados gradualmente observados na construção de diálogos saudáveis e evolutivamente mais abertos, permitindo acolher e compreender, toda a angústia gerada pelo momento.

O modelo de avaliação formativa adotado para cômputo da menção final dos alunos mostrou-se adequado para atender ao objetivo da disciplina neste momento de Cisne Negro, na medida em que, considerou-se todo o decurso de atividades e tarefas teóricas aplicadas pelo docente e ao mesmo tempo, atendeu às normativas institucionais estabelecidas.

A importância da continuidade das aulas, e em especial a oferta da disciplina TFAE no cenário Cisne Negro, contribuiu para envolver os discentes na manutenção de suas atividades de ensino-aprendizado demonstrando o quanto é relevante à ininterrupção na formação de profissionais para as necessidades do mundo do trabalho.

A construção de novas práticas pedagógicas está em curso, os experimentos apresentaram múltiplas possibilidades de resultados quanto à aplicação de aulas no ERE. Neste tempo de modos diversos, de fazeres e aprenderes remete ao aprimoramento, à reinvenção da didática e ao desenvolvimento de uso das mídias digitais. Não é trivial a organização de tempos de gestão; institucional, didático e o de aprendizagem discente. É um novo processo de adaptação para a comunidade acadêmica em geral.

As experiências do ERE deverão acelerar mudanças que já estavam ocorrendo com o uso das tecnologias da informação, é a transformação digital em curso, aumentando a velocidade de respostas, agilizando atendimentos personalizados e aprimorando a performance de ações, elementos do mindset digital. Tais experiências, socializadas e acompanhadas de resultados permitirão discussões que contribuirão no aperfeiçoamento do ensino e em estratégias metodológicas mais eficazes.

A reinvenção no caos e o ensinamento profundo de aceitação de modelos que não são compreensíveis, no primeiro momento, e a rejeição de modelos que consolidam opinião formada, encerram mais uma lição do Cisne Negro. Dessa forma, o tema não se esgota nesse artigo, pesquisas futuras com olhar ampliado sobre o mindset digital e na busca incansável pelo aprendizado e saber, alçará o ensino superior a patamares de mudanças profundas e o ensino híbrido avançado é a Lógica, do pós Cisne Negro.

\section{Referências}

Arruda, E. P. (2020). Educação Remota Emergencial: elementos para políticas públicas na educação brasileira em tempos de Covid-19. EmRede - Revista De Educação a Distância, 7 (1), 257-275.

Bergmann, J., \& Sams, A. (2016). Sala de aula invertida: uma metodologia ativa de aprendizagem. LTC.

Ministério da Educação (2001). Portaria $\mathrm{n}^{\circ} 2.253$, de 18 de outubro de 2001. Dispõe sobre a introdução nas instituições de ensino superior do sistema federal de ensino, na organização pedagógica e curricular de seus cursos superiores reconhecidos, a oferta de disciplinas que, em seu todo ou em parte, utilizem método não presencial, com base no art. 81 da Lei $n^{\circ}$ 9394, de 1996. https://www2.camara.leg.br/legin/marg/portar/2001/portaria-2253-18-outubro-2001412758-publicacaooriginal-1-me.html

Ministério da Educação (2004). Portaria n ${ }^{\circ} 4.059$, de 10 de dezembro de 2004. Dispõe sobre a introdução, na organização pedagógica e curricular de cursos superiores reconhecidos, a oferta de disciplinas integrantes do currículo que utilizem modalidade semipresencial, com base no art. 81 da Lei $n^{\circ} 9.394$, de 1996, e no disposto nesta Portaria. http://portal.mec.gov.br/sesu/arquivos/pdf/nova/acs_portaria4059.pdf

Ministério da Educação (2016). Portaria $n^{\circ} 1.134$, de 10 de outubro de 2016. Revoga a Portaria MEC no 4.059, de dezembro de 2004, e estabelece nova redação para o tema. https://www.in.gov.br/web/dou/-/portaria-no-1-134-de-10-de-outubro-de-2016-22055503-22055503

Ministério da Educação (2018). Portaria n 1.428, de 28 de dezembro de 2018. Dispõe sobre a oferta, por Instituições de Educação Superior - IES, de disciplinas na modalidade à distância em cursos de graduação presencial. https://www.in.gov.br/materia//asset_publisher/Kujrw0TZC2Mb/content/id/57496468/do1-2018-12-31-portaria-n-1-428-de-28-de-dezembro-de-2018-57496251

Ministério da Educação (2019). Portaria no 2.117, de 6 de dezembro de 2019. Dispõe sobre a oferta de carga horária na modalidade de Ensino a Distância EaD em cursos de graduação presenciais ofertados por Instituições de Educação Superior - IES pertencentes ao Sistema Federal de Ensino. https://www.in.gov.br/en/web/dou/-/portaria-n-2.117-de-6-de-dezembro-de-2019-232670913

Ministério da Educação (2020). Portaria n ${ }^{\circ}$ 343, de 17 de março de 2020. Dispõe sobre a substituição das aulas presenciais por aulas em meios digitais enquanto durar a situação de pandemia do Novo Coronavírus - COVID-19. Brasília: Ministério da Educação. https://www.in.gov.br/en/web/dou/-/portaria-n343-de-17-de-marco-de-2020-248564376 
Research, Society and Development, v. 10, n. 1, e40510111916, 2021

(CC BY 4.0) | ISSN 2525-3409 | DOI: http://dx.doi.org/10.33448/rsd-v10i1.11916

Galegale, G. P., \& Brólio, D. R.(2019). Institucionalização do ensino a distancia no Brasil - a busca pela legitimação. Brazilian Journal of Development. 5 (7), $10271-10283$

Gómez, A. I. P. (2015). Educação na Era Digital: a escola educativa. Editora Penso.

Hodges, C. et al. (2020). The difference between emergency remote teaching and online learning. EDUCAUSE Review. 27(Mar). https://er.educause.edu/articles/2020/3/the-difference-between-emergency-remote\%20teaching-and-online-learning

Horn, M. B. \& Staker, H. (2015). Blended usando a inovação disruptiva para aprimorar a educação. Editora Penso.

Iftakhar, S. (2016). Google Classroom: what works and how? Journal of Education and Social Sciences, 3(Feb). http://jesoc.com/wpcontent/uploads/2016/03/KC3_35.pdf

Moore, M. G. (1993). Theory of transactional distance. Revista de Aprendizagem Aberta e a Distância p.03-38.

Moran, J. M. (2015). Mudando a educação com metodologias ativas. Coleção Mídias Contemporâneas.

Organização Pan-Americana de Saúde (OPAS) (2020). Folha informativa - COVID-19. https://www.paho.org/bra/index.php?option=com_conte nt\&view=article \&id=6101: covid19\&Itemid $=875$

Pereira, et al. (Org.) (2007). AVA: Ambientes Virtuais de Aprendizagem em diferentes contextos. Editora Ciência Moderna Ltda.

Pereira, A. S. et al. (2018). Metodologia da pesquisa científica. UFSM, NTE.

Rabelo, E. H. (1998). Avaliação: novos tempos e novas práticas. Vozes.

Silva, D. S. et al. (2020). Alternativa de ensino em tempo de pandemia. Research, Society and Development. 9 (9), 1-17.

Taleb, N. N. (2015). A Lógica do Cisne Negro. O impacto do altamente improvável. Best Business. 